\title{
Tibetan Prayer-Wheels.
}

\section{A. R. Wright}

To cite this article: A. R. Wright (1904) Tibetan Prayer-Wheels., Folklore, 15:3, 332-333, DOI: 10.1080/0015587X.1904.9719414

To link to this article: http://dx.doi.org/10.1080/0015587X.1904.9719414

册 Published online: 06 Feb 2012.

Submit your article to this journal

山 Article views: 12

Q View related articles $₫$ 


\section{Tibetan Prayer-Wheels.}

\section{(Exhibited at Meeting of Society. See Plate VI, and p. 243.)}

Tus table prayer-wheel shown to the right of Plate VI. has an outer cylinder of copper six inches high and ornamented with bosses containing turquoises. In both the upper and lower panels formed by the central rib is embossed in ancient Indian ranja characters (of the seventh century), the well-known mystical formula, Om/ mani pädme $\mathrm{hm} /(\mathrm{Om} /$ the jewel in the lotus! $\mathrm{Hm}$ !) The side handles may be intended to suspend the wheel or to facilitate carriage. On removing the dome-shaped lid, an inner brass cylinder (seen through the apertures of the outer cylinder in the Plate) is found, through which passes an axle resting in a footstep in the bottom of the outer cylinder and ending, above the outer lid as shown, in a tapering screwed part which can be easily twirled by the fingers. On removing the lid of the inner cylinder, a tightly packed mass of scrolls is visible, which is rotated when the axle is twirled. Seeing a prayer is thought to be as good as saying it, and passing it before one as good as seeing it (even if it is out of sight in a revolving prayer-wheel). The prayer scrolls are usually covered with numberless repetitions of the sacred formula already mentioned, which is expected to free the user from the pains and discomforts of a rebirth after the present life, and to end the illusion of existence. (See Waddell's The Buddhism of Tibet, pp. I48-9, where an illustration of a formula is given.) Almost invariably the scrolls contain only repetitions of a single prayer to a single deity, but in the example shown the scrolls are filled with invocations to four deities, the white, black, yellow, and green gods, who control the powers of evil at the four cardinal points. Each prayer opens with the proper invocations or mantras for these gods, viz. Om/ mani pädme hm/ (for Chä-rä-si (Avalokita) the white); Om I Vajrapani hm phät! (for Cha-na-dorje (Vajrapani) the black); Om / a-ra-pa-ca-na-dhil (for Jam-yang (Mañjughosha) the yellow); and Om/ Tä-re tut-tä-re ture svä-häl (for Dölma jan-k'u (''lărã) the green). The prayer itself, translated, runs, "The yellow god, the white god, the black god, the green god, please kindly to take us all up with you, and do not leave us unprotected, but destroy our enemies. Ye gods, who can do 


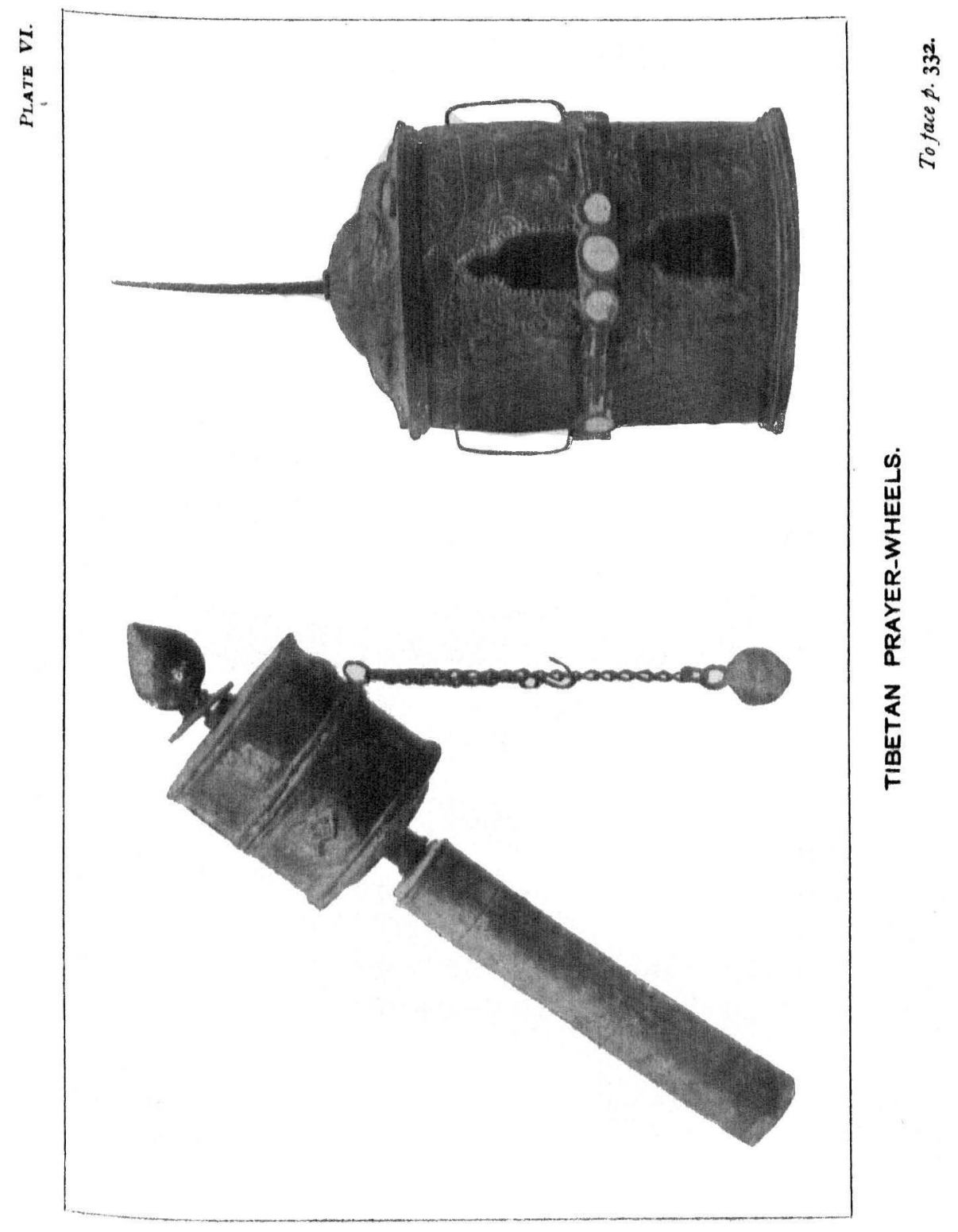


PI.ATE VII.

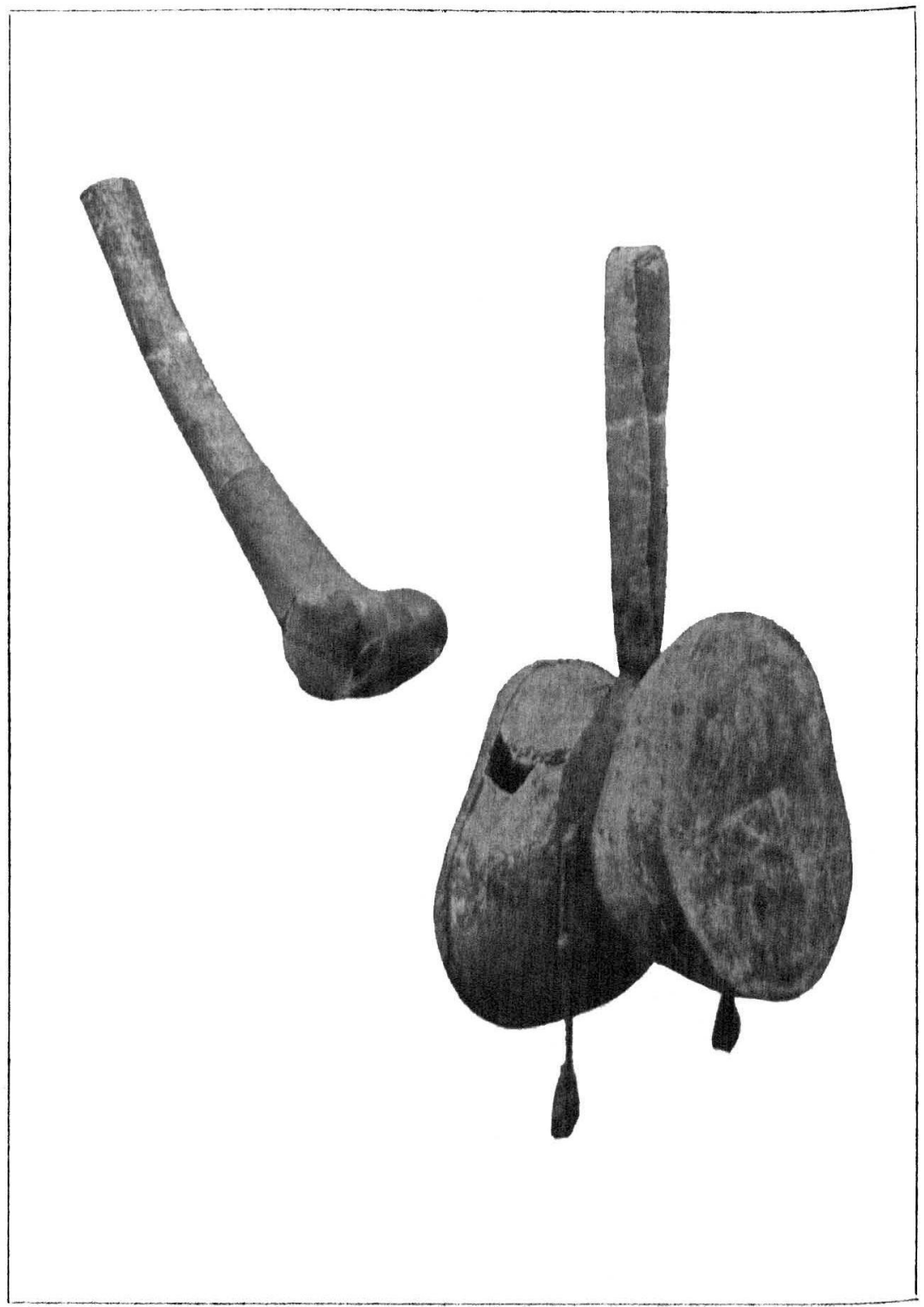

TIEETAN DRUM AND TRUMPET.

To face p. 333. 
everything for us, and who are the owners of our souls and lives, keep us safe with you."

The mantra or formula appropriate to the contained prayers must he repeated before a wheel is turned, and also at the end of the rotation, or else no merit will be gained. The mantra should also be repeated as often as possible while the turning is going on, and the faster the turning the greater the merit. It is also necessary that the wheel shall be turned only in the direction in which a person would go keeping his right side always to the axle. To turn in the reverse direction is to undo all that has been previously done by a right turning.

The smaller prayer-wheel, mounted on a long wooden handle and seen to the left of the Plate, is for hand use, and is kept in motion with very little effort by the help of the chain and weight. $A$ hook and chain are also provided for the suspension of the wheel, which contains the usual formula, and has embossed on it the "eight glorious emblems" found in Buddha's footprints, viz. the golden fish, umbrella, conch-shell trumpet of victory, lucky diagram, victorious banner, vase, lotus, and wheel.

A. R. WRIGIT.

\section{Tiretan Drum and Trumpet.}

\section{(Exhibited at Meeting of Society. See Plate VII. and p. 243.)}

Tue object to the right of Plate VII. is a drum made of the caps of two human skulls secured together at their apices, and with their bases covered by human skin. The drum is beaten by jerking it from one side to the other by the supporting band, so that the two hanging leather bobs strike the skin coverings.

The other object shown is a kaindin, or trumpet made of a human thigh-bone, the lower part of which is covered with human skin. Such a trumpet "is sometimes encased in brass, with a wide copper flanged extremity, on which are figured the three eyes and nose of a demon, the oval open extremity being the demon's mouth. In the preparation of these thigh-bone trumpets the bones of criminals or those who have died by violence are preferred, and an elaborate incantation is done, part of which consists in the IAma eating a portion of the skin of the bone; otherwise its blast would not be sufficiently powerful to summon 